\title{
German institutes face closure after review
}

Munich. The future of some of Germany's 82 'blue-list' institutes may be in doubt as a result of a review of the research activities of all such institutes by the Wissenschaftsrat, Germany's influential science council.

Blue-list institutes form the 'fourth pillar' of Germany's non-university research, after the Max Planck Society (MPG), the Fraunhofer Society and the national research centres. Funded jointly by federal and Länder governments, they carry out a variety of research and service activities in the social and natural sciences.

After reunification, many former East German establishments were added to the 'blue list' as a stopgap measure, as neither the MPG nor the universities were able to absorb them. Largely as a result, the number of such institutes has risen from 48 to 82 .
The body responsible for the institutes, Wissenschaftsgemeinschaft Blaue List (WBL) was reorganized in 1993 to take this into account. But its increased significance has come in for some sharp criticism (see Nature 363, 482; 1993).

As a result, the Bund-Länder-Kommission (BLK), which arranges political and financial agreements between federal and Länder governments, decided to implement a review of the activities carried out under the umbrella of the WBL, likely to last for five years, as a concluding chapter to its reunification efforts.

Following the first stage of this review, in which five blue-list establishments were assessed, the Wissenschaftsrat has now recommended that funding be withdrawn from two of them. According to the science

\section{Combined beams bring stars into focus}

London. A new type of optical telescope, designed and built at the Mullard Radio Astronomy Observatory at the University of Cambridge and costing less than one thousandth the price of the orbiting Hubble Space Telescope (HST), has produced the sharpest ever images of Capella (below), two closely spaced stars 40 light years distant from Earth.

No other telescope, including the HST, has been able to resolve these stars, which are separated by a distance less than that between the Earth and the Sun. But the Cambridge Optical Aperture

Synthesis Telescope (COAST), which is pictured right, cost only $£ 850,000$ (US\$1.3 million). The telescope will be able to discern detail in stars in a manner equivalent to resolving "the letters of a car number plate from a distance of 1,000 km", says Peter Warner, assistant director of research at the Mullard Laboratory.

The telescope is based on interferometry. It combines light beams from an array of up to four smaller telescopes, each pointing towards the chosen star, and the desired image is then reconstructed electronically from the recombined beams. This technique is widely used in radioastronomy. Until now, however, it could not be used at the much shorter optical wavelengths, where a higher degree of precision and stability is needed to recombine the separate beams accurately.

The challenge for COAST's designer, John Baldwin, professor of physics at the Mullard Laboratory, and his team was to produce a design that would allow for thermal expansion in the telescope's parts, possible ground movement and temperature changes.

The beam from each telescope passes through a plastic tube, which isolates it from the atmosphere, and enters a 'beam-combining building', a 32-metre-long corrugated tunnel 2.4 metres high. Stability is provided by submerging the tunnel in $\mathbf{3 0 0}$ tonnes of earth covered with grass.

Baldwin and his team also had to

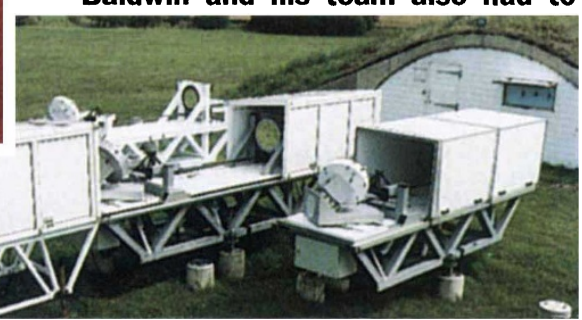

maintain the beam's path length, which would otherwise be altered by the Earth's rotation and the star's movement. This was done by allowing light to fall on to a mirror mounted on a movable but frictionless trolley. A laser tracks the minute changes in the beam's path, and the trolley's position is altered accordingly.

COAST was paid for by the Particle Physics and Astronomy Research Council. The designers at Mullard are now hoping to build a second version which they expect to have a 10-fold better resolution

Ehsan Masood council, both the Institute for Economic Research in Hamburg and the Department of Earth Sciences at the Office of Soil Research (NLfB-GGA) in Lower Saxony, have been performing badly in terms of publication, cooperation with universities and general efficiency.

The Wissenschaftsrat had already recommended to the BLK, which is responsible for the final decision, that funding be withdrawn from the Institute for Mineral Oil Research (IfE) in Lower Saxony.

The Wissenschaftsrat has said that it does not doubt the "general importance" of the work of these institutes. But their future now looks bleak, as termination of their contracts with the WBL would mean funding running out by the end of 1997. At a time of tight research budgets, neither their host Land nor a federal ministry is likely to take on the costs of running institutes that carry out a relatively low level of research, and as a result, the more productive research projects could end up being taken over by university departments.

Neither the BLK nor the affected institute directors are willing to discuss the possibility of closure. Dagobert Kessel, head of the IfE, says confidently that "there will be some kind of mineral oil research even in the year 2000", while Ralph Hämel, head of NLfB-GGA, complains of the "thoughtless assessment" of the Wissenschaftsrat, and says that he is planning to object to its conclusions.

But Michael Lankeit, administrative vice president of the WBL, argues that the Wissenschaftsrat's assessments are fair. "My colleagues must finally recognize that the Wissenschaftsrat is serious about it," he says.

Lankeit is aware that the Wissenschaftsrat operates under political and financial pressure. Although the budget of the WBL is being held constant, eight new institutes have been recommended for admission by the Wissenschaftsrat. As 16 establishments are now to be assessed every year, he warns all WBL institutes against a complacent "why should it happen to us" attitude.

Having asked the Wissenschaftsrat to carry out the evaluation, the BLK is expecting results, says Lankeit, as part of its efforts to consolidate Germany's system of research funding and to boost quality control mechanisms that have been strained by the demands of reunification and the economic recession (see Nature 377, 466; 1995).

At the same time, however, when the WBL agreed to the evaluation of its institutes, it did so in the hope that it will eventually be given similar control over its finances to MPG and the Fraunhofer Society. Until now, the WBL has not been able to reallocate any savings in its budget, but has been required to pass these back to the Bund and the host Land.

Quirin Schiermeier 